\title{
Особенности вегетации интродуцированного сорта винограда Кёхо в стрессовых погодных условиях умеренно континентального климата юга России
}

\author{
Дмитрий Владимирович Дергачев ${ }^{1}$, канд. биол. н., директор; \\ Марина Дмитриевна Ларькина ${ }^{1}$, канд. с.-х. н., зам. директора по науке; e-mail: maran-1@yandex.ru; \\ Валерий Семенович Петров ${ }^{2}$, д-р с.-х. н., руководитель ФНЦ "Виноградарство и виноделие"; e-mail: petrov_53@mail.ru; \\ Михаил Иванович Панкин ${ }^{2}$, д-р с.-х. н., вед. науч. сотр. НЦ "Виноградарство" \\ ${ }^{1} 000$ «Инновационная Компания «Таманский Биотехнологический Центр», ул. Таманская, 5, г. Темрюк, Краснодарский край, Россия \\ ${ }^{2}$ Федеральное государственное бюджетное научное учреждение "Северо-Кавказский федеральный научный центр садоводства, \\ виноградарства, виноделия". 350901, г. Краснодар, ул. 40 лет Победы, 39, Россия
}

\begin{abstract}
Исследования интродуцированного японского сорта винограда Кёхо выполнены в нестабильных погодных условиях умеренно континентального климата юга России, в Черноморской зоне виноградарства Краснодарского края в условиях температурного и водного стрессов 2018 года. В период активной вегетации (май - август) сумма активных температур воздуха была на $197^{\circ} \mathrm{C}$ больше среднемноголетней нормы, количество атмосферных осадков было меньше нормы в 3,7 раза и составило 47 мм. В аномальных погодных условиях интродуцированный сорт винограда Кёхо показал высокую адаптивность к нестабильным погодным условиям в форме активного роста и прохождения фенологических циклов. При остром дефиците атмосферных осадков и повышенной инсоляции продолжительность вегетации винограда Кёхо от распускания почек до полной физиологической зрелости ягод была равна 119 дней, на 5 дней меньше, чем у контрольного сорта Бригантина и на 3 дня меньше, чем в среднем по большой группе столовых сортов разного эколого-географического происхождения, расположенных рядом на Анапской ампелографической коллекции. Начало фазы распускания почек, роста побегов и соцветий наблюдалось 15 апреля, у контрольного сорта на 4 дня раньше, у сортов ампелографической коллекции на 6 дней позже. Продолжительность этой фазы вегетации у изучаемого сорта составила 54 дня, больше на 11 дней чем у контрольного сорта и на 9 дней чем у столовых сортов ампелоколлекции. Цветение у сорта Кёхо начиналось 7 июня, на 15 дней позже чем у контрольного сорта Бригантина и на 3 дня чем у группы столовых сортов на ампелоколлекции. Продолжительность периода от начала цветения до начала созревания ягод у сорта Кёхо в экологических условиях 2018 года составила 50 дней, что на 4 дня короче, чем у контрольного сорта и на 3 дня короче, чем у сортов на ампелоколлекции. Интенсивность роста ягод была более высокой по сравнению с контролем и группой столовых сортов в ампелоколлекции. Полная физиологическая зрелость ягод у изучаемого сорта наступила 11 августа, практически одновременно с контролем - 12 августа.
\end{abstract}

Ключевые слова: виноград; интродукция; сорт; вегетация; стресс-факторы; адаптация
O R I G I N A L R E S E A R C H

\section{Vegetation characteristics of introduced grapevine cultivar 'Këho' under the effect of stress weather conditions of the moderate continental climate of the South of Russia}

Dmitry Vlasimirovich Dergachev ${ }^{1}$, Marina Dmitrieyevna Larkina ${ }^{1}$, Valerii Semyonovich Petrov ${ }^{2}$, Mikhail Ivanovich Pankin ${ }^{2}$

${ }^{1}$ OOO Innovacionnaya Kompaniya Tamanskij Biotexnologicheskij Centr, 5 Tamanskaya Str., Temryuk, Krasnodar Krai, Russia

${ }^{2}$ Federal State Budgetary Scientific Institution North Caucasian Regional Research Institute of Horticulture and Viticulture, 39, 40-let Pobedy Str., Krasnodar, 350901

The study of introduced Japanese grapevine cultivar 'Këho' was carried out in unstable weather conditions of moderately continental climate of the South of Russia, in the Black Sea viticultural zone of the Krasnodar Krai under temperature and water stress of 2018. During the active vegetation season (May - August), the accumulated effective temperatures made $197^{\circ} \mathrm{C}$ above the long-time average annual, the amount of precipitation was 3.7 times less than normal, and amounted to $47 \mathrm{~mm}$. Under the effect of abnormal weather conditions, the introduced grapevine cultivar 'Këho' demonstrated high adaptability to erratic weather conditions during the active growth phase and passage of phenological cycles. Under acute atmospheric precipitation deficit and increased insolation, the duration of 'Këho' grapevine vegetation from bud break to full physiological berry ripeness made 119 days, which is 5 days less as compared to control cultivar 'Brigantina' and 3 days less than the average for a large group of table cultivars of various ecological and geographical origin, located in the nearby Anapa ampelographic collection. The start of the bud break, shoot and inflorescence growth phase was observed on April 15; it happened 4 days earlier for the control cultivar, and 6 days later for the cultivars in the ampelographic collection. The duration of this vegetation phase for the studied cultivar was 54 days, which by 11 days exceeded that of the control cultivar and by 9 days that of the table cultivars in the ampelographic collection. The bloom of 'Këho' began on June 7 - 15 days later than that of the control cultivar 'Brigantina' and 3 days later as compared to the group of table cultivars in the ampelographic collection. Duration of the early bloom to veraison period of 'Këho' grapes in the ecological conditions of 2018 made 50 days, which was 4 days shorter than that of the control cultivar and 3 days shorter as compared to the cultivars in the ampelographic collection. The berry growth was more intensive as compared to the control and the group of table cultivars in the ampelographic collection. Berries of the studied cultivar reached full physiological ripeness on August 11, almost simultaneously with the control - on August 12.

Key words: grapes; introduction; variety; vegetation; stress factors; adaptation.

\section{Как цитировать эту статью:}

Дергачев Д.В., Ларькина М.Д., Петров В.С., Панкин М.И. Особенности вегетации интродуцированного сорта винограда Кёхо в стрессовых погодных условиях умеренно континентального климата юга России// «Магарач». Виноградарство и виноделие, $2019 ; 21(3) ;$ С. $223-228$. DOI 10.35547/IM.2019.21.3.007

\section{How to cite this article:}

Dergachev D.V., Larkina M.D., Petrov V.S., Pankin M.I. Vegetation characteristics of introduced grapevine cultivar 'Këho' under the effect of stress weather conditions of the moderate continental climate of the south of Russia. Magarach. Vinogradarstvo $i$ Vinodelie = Magarach. Viticulture and Winemaking, 2019; 21(3):223-228. DOI 10.35547/IM.2019.21.3.007 (in Russian)

удК $634.8: 631.52$

Поступила 19.06.2019

Принята к публикации 20.08.2019

(C) Авторы, 2019 
$\mathrm{B}$ ведение. Фенология является важнейшим биоцогическим признаком виноградного растения. КажАый сорт винограда обладает определенными признаками при прохожАении отАемьных фенологических цикмов в период вегетации [1-5].

Вегетационный период и отдельные фазы вегетации винограда определяются прежде всего биомогическими особенностями сортов. В Аействующем российском сортименте винограда по фенологическим признакам существенно размичаются столовая и техническая группы сортов. В группе столовых сортов преобладают ранние и раннесредние генотипы с ускоренным прохождением фаз вегетаций, в группе технических, наоборот, Аоминируют среднепозАние и позАние - с более Алительным периодом вегетации [6]. Исследованиями установмено вмияние размера семян на начало созревания ягод винограда. Чем больше фракция семян, тем позАнее начиналось созревания ягоА в связи с гормональной перестройкой [7].

Кроме биологических свойств на характер и сроки прохождения фаз вегетации вАияют условия среды обитания культуры винограда и особенно температурный режим [8-11]. На основе анализа большого количества сортов $\Lambda$ азаревский М.А. [12] показац веАущую роль тепла в прохожАении фаз вегетации винограда. Повышение температуры воздуха значительно уменьшает периоА постэмбрионацьного развития цветочных органов и приближает сроки цветения ви-

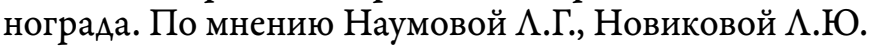
[13], основным климатическим фактором, вызывающим уменьшение периода вегетации от начала цветения Ао полного созревания ягоА и от распускания почек АО полной зрелости ягоА, явцяется температура воздуха выше $20^{\circ} \mathrm{C}$.

В Швейцарии на плантациях, заложенных в 1915 году, наблюдалось циклическое развитие винограда в условиях изменения климата. ГАобацьное потепление в последние 20 мет (1990 - 2009 гг.) значительно укоротило продолжительность периодов цветения и созревания винограда. Такие же явления наблюдали в период межАу 1940 и 1950 гг. [14]. Анацогичные явления отмечали в условиях изменения умеренно континентацьного кмимата на юге России. Потепцение кмимата на виноградниках Анапской зонацьной опытной станции виноградарства и виноделия (г.-к. Анапа) сопровожАалось изменением начала фаз вегетации. В настоящее время в западноевропейской эколого-географической группе технических сортов винограда дата распускания почек отмечается на 2 Аня позже, чем в 1938-1941 годах, а начамо цветения на 7 дней раньше. У столовых сортов дата распускания почек стала на 1 Аень позже, цветения на 1 Аень раньше. Произошло сокращение периода от распускания почек до начаца цветения у технических сортов на 9 Аней, у столовых - на 2 Аня. Также сократился период от начала цветения до начаха созревания на 3 Аня у технических и на 6 Аней у столовых сортов. Аналогичная тенденция у технических сортов восточной эколого-географической группы и у сорта Пухляковский, относящегося к сортам побережья Черного моря [15]. КАиматические условия оказывают влияние не только на период цве- тения, но и на прорастание и жизнеспособность пыцьцы [16].

Тренды изменений состава и качества ягод кучше всего объясняются ростом количества Аней с высокой температурой в периоА цветения и созревания и уменьшением количества осадков в период созревания [17]. Изменение кмимата приводит к значительным изменениям фенологии, причем смещение раньше набцюдалось у ранних и среАних сортов, чем у позАних [18]. Тренаы к потеплению в большинстве регионов повлияли на изменения в фенологических цикмах винограАа в Европе. Изменения типично больше в минимальных температурах, чем в максимальных, со средним потеплением на $1,7^{\circ} \mathrm{C}$ в течение вегетационного периода и ростом на 300 вегетационных градусо-дней и значений индекса Углина в течение последних 50 мет [19]. Анализ показал наиболее значимые связи винограАарство-кцимат межАу среАней, максимацьной температурой воздуха и вегетационными граАусо-Анями [20].

Аинамика прохождения фаз вегетации также зависит и от почвенных условий [21]. В Швейцарии наблюдали влияние почв, кмимата и топографии на фенологию винограда. Разные условия обуславливали размичия во времени распускания почек и Аальнейшего развития растений винограда [22].

Особенности прохождения отдельных фаз вегетации в годичном цикле онтогенеза винограда имеют большое практическое значение в организации функционально направленного устойчивого винограАарства. Сорта с разными сроками созревания ягоА используют Аля формирования конвейера потребления винограда в свежем виде и промышкенной переработки [23]. А^я агроэкологических зон виноградарства с периодически повторяющимися ранневесенними заморозками селекция направлена на создание и практическое использование сортов с более поздним сроком распускания зимующих глазков, чтобы избежать температурные повреждения на молодых растущих побегах в период возвратных холодов [24].

Интродукция сортов чаще всего связана с существенными изменениями экологических условий, вАияющих на произрастание винограда и прохождение его фенологических цикмов. В этой связи целью Аанных исследований стало выявление особенностей вегетации интродуцированного японского сорта винограда Кёхо в стрессовых погодных условиях умеренно континентального кмимата юга России аця использования в селекции и практическом производстве.

\section{Методы исследования}

Исследования выполнены в стрессовых погодных условиях умеренно континентацьного кмимата Черноморской зоны виноградарства Краснодарского края в 2018 году (ООО «ИК «Таманский биотехнологический центр», х. Белый). В качестве объекта исследований использовали интродуцированный японский сорт винограда Кёхо. Японский европейско-американский гибриА Кёхо произошел от скрещивания генотипов Сентиниал и Ивахара быстрорастущий. Сорт отличается большой симой роста, крупной грозАью привлекательной формы. Ягоды очень крупные, 
40,0

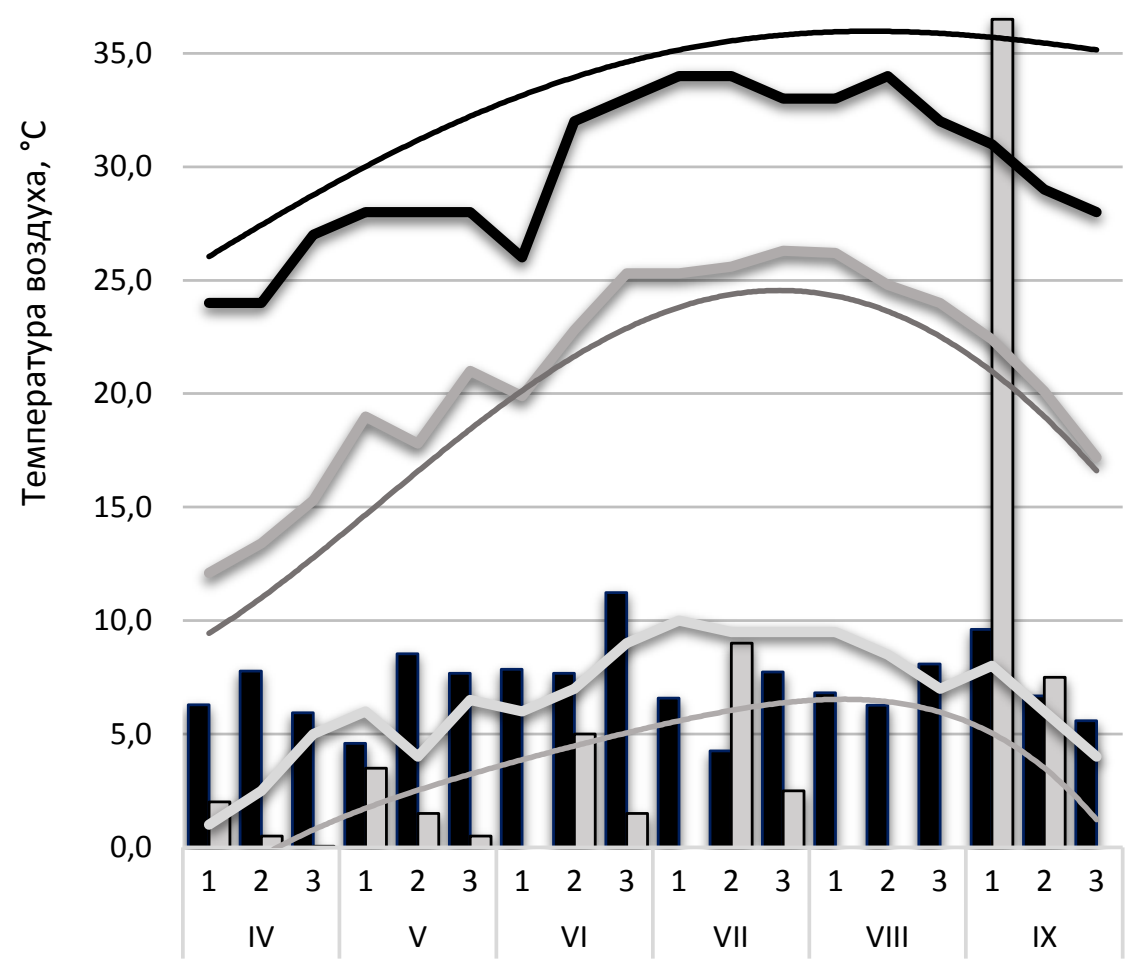

80,0

70,0

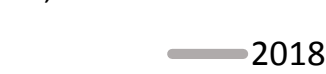

50,0

40,0

30,0

20,0

10,0

0,0

2018
1977-2018

max 2018

$\min 2018$

- Полиномиальная

(1977-2018)

- Полиномиальная (мах 1977-2018)

- Полиномиальная (міn 1977-2018)

Рис. Погодно-климатические условия вегетации винограда Кёхо, 2018 г.

Fig. Weather and climatic conditions during vegetation of 'Këho' grapes, 2018

массой 16 - 17 г, темно-фиолетовой окраски, овацьные, высоких вкусовых достоинств. Ягоды созревают рано и имеют упругую мякоть. Гибрид обладает высокой продуктивностью. Положительные хозяйственно ценные признаки характерны Аля винограда, выращенного в агроэкологических условиях Японии. Они существенно отличаются от российских. За контроць бым принят столовый симьнорослый сорт винограАа Бригантина (Молдова $\times$ Кардинал) местной селекции АЗОСВиВ, ввеАенный в Государственный реестр семекционных Аостижений, Аопущенных к использованию с 2009 года. Сорт винограда сверхраннего срока созревания. ГрозАи крупные, ширококонической формы, среАней плотности, массой 420 г. Ягоды среАние ими крупные, Ао 7 г, округлой формы, темно-красные. Мякоть сочно-мясистая. Кожица среАней прочности. Вкус гармоничный. Урожай с куста 8 - 9 кг при массовой концентрации сахаров 17 г/100 см ${ }^{3}$ и титруемой кислотности 7,8 г/Ам ${ }^{3}$. Сорт отмичается устойчивостью к мицАью, оиАиуму, серой гници, вреАителям. Устойчивость к морозу повышенная. Аегустационная оценка свежего винограда 8,6 бамиа.

Наблюдения за фенологическим развитием растений в период их вегетации проводими по методике Аазаревского [25].

\section{Результаты и обсуждение исследований}

В Черноморской зоне виноградарства Краснодарского края, на территории размещения изучаемых насаждений продолжительность периода вегетации Аостигает 212 дней. Сумма активных температур возАуха состав яет $3750^{\circ} \mathrm{C}$. За послеАние 42 года по Аанным метеостанции г. Темрюк среАнесуточная темпе- ратура воздуха за год равна $11,9^{\circ} \mathrm{C}$, во время активной вегетации (май - сентябрь) - 20,9 ${ }^{\circ} \mathrm{C}$. Минимацьная температура в период зимовки винограда опускается Ао $-24^{\circ} \mathrm{C}$, максимацьная во время вегетации достигает $38^{\circ} \mathrm{C}$. В Аинамике умеренно континентацьный киимат характеризуется мокацьными изменениями, частыми аномацьными проявцениями в форме низкотемпературных и водных стрессов. С 1977 г. среднегодовая температура воздуха увеличимась на $1,4{ }^{\circ} \mathrm{C}$, максимацьная - на $2,8^{\circ} \mathrm{C}$, минимацьная - напротив, снизи$\Lambda$ ась на $4,0^{\circ} \mathrm{C}$. Сумма атмосферных осадков в период высокой потребности растений во вцаге Аля активного роста ягоА винограда (II. июнь - III. август) уменьшилась на 45 мм.

Исследуемый 2018 г. характеризуется высокотемпературным и низководным стрессорами. В период активной вегетации (май - август) сумма активных температур воздуха быма на $197^{\circ} \mathrm{C}$ больше среднемноголетней нормы и составцяла $2780{ }^{\circ} \mathrm{C}$. СреАнесуточная температура в этот период превышаца норму на $1,6^{\circ} \mathrm{C}$ и была равна $23,1^{\circ} \mathrm{C}$. Комичество атмосферных осадков бымо меньше нормы в 3,7 раза и составимо 47 мм (рис.).

Результаты изучения интродуцированного сорта винограда Кёхо в стрессовых погодных условиях 2018 года показали ценные биологические признаки генотипа - высокую адаптивность к нестабимьным погодным условиям умеренно континентацьного киимата юга России по фенологическим показателям - активному росту и полноценному прохожАению фаз вегетации. При остром Аефиците атмосферных осаАков и повышенной инсоляции продолжительность вегетации 
Таблица. Фенологические циклы винограда столовых сортов, ООО «ИК «ТБЦ», 2018 г.

Table. Phenological cycles of table cultivars, OOO IK TBC, 2018

\begin{tabular}{|c|c|c|c|c|c|c|c|}
\hline \multirow[b]{2}{*}{ Сорт } & \multirow[b]{2}{*}{ ПроисхожАение сорта } & \multicolumn{4}{|l|}{ Начало } & \multirow{2}{*}{$\begin{array}{l}\text { Полная физи- } \\
\text { ологическая } \\
\text { зрелость ягоА }\end{array}$} & \multirow{2}{*}{$\begin{array}{l}\text { Количество Аней от } \\
\text { распускания почек Ао } \\
\text { полной физиологиче- } \\
\text { ской зремости ягоА }\end{array}$} \\
\hline & & $\begin{array}{l}\text { распуска- } \\
\text { ния почек }\end{array}$ & цветения & $\begin{array}{l}\text { созрева- } \\
\text { ния ягоА }\end{array}$ & $\begin{array}{l}\text { созревания } \\
\text { побегов }\end{array}$ & & \\
\hline Кёxo & $\begin{array}{l}\text { Сентиниам × Ивахара } \\
\text { быстрорастущий } \\
\text { (Япония) }\end{array}$ & 15.4 & 7.6 & 26.7 & 29.7 & 11.8 & 119 \\
\hline Бригантина (контроль) & $\begin{array}{l}\text { Молдова } \times \\
\text { Кардинац } \\
\text { (Россия, АЗОСВиВ) }\end{array}$ & 11.4 & 23.5 & 16.7 & 18.7 & 12.8 & 124 \\
\hline $\begin{array}{l}\text { Группа столовых сортов } \\
\text { Анапской ампемографи- } \\
\text { ческой комлекции [26] }\end{array}$ & & 21.4 & 4.6 & 26.7 & 29.7 & 20.8 & 122 \\
\hline
\end{tabular}

винограда от распускания почек Ао полной физиологической зрелости ягод у изучаемого сорта Кёхо была равна 119 Аней, что характерно Аля ранних сортов. Это на 5 Аней меньше по сравнению с контроцьным сортом Бригантина и на 3 Аня меньше, чем в среАнем по группе столовых сортов, рядом расположенных на Анапской ампелографической комлекции. В Черноморской зоне по Аанным Аесятицетних набцюдений на Анапской ампемографической комцекции у группы столовых сортов разного эколого-географического происхождения - Convar occidentalis Negr. (западноевропейские), Convar orientalis Negr.(восточные), Convar pontica Negr. (бассейна Черного моря) обычно продомжительность вегетации от распускания почек Ао полной физиологической зрелости ягоА составцяет 122 АНЯ.

Начамо фазы распускания почек, роста побегов и соцветий у сорта Кёхо набцюдацось 15 апреця, у контрольного сорта на 4 Аня раньше, 11 апремя. У группы столовых сортов на Анапской ампелографической комлекции обычно это происходит на 6 Аней позже - 21 апреля, в том числе у запаАно-европейской группы сортов 20 апремя, у сортов восточной группы - 22 апреля, бассейна Черного моря - 21 апреля, межвидовых гибридов - 21 апремя и внутривидовых гибридов - 19 апреля [26]. Продолжительность этой фазы вегетации у изучаемого сорта составима в 2018 году 54 Аня, это на 11 Аней бомьше, чем у контрольного сорта и на 9 Аней, чем у столовых сортов ампемокомлекции. Бомее позАнее начамо вегетации сорта винограда Кёхо в условиях юга России является положитемьным признаком, что позвоцяет уйти растению от повреждений возвратными заморозками.

Цветение у сорта Кёхо начинацось 7 июня, на 15 Аней позже, чем у контромьного сорта Бригантина и на 3 Аня, чем у группы столовых сортов на ампецокоммекции.

Продолжительность периода от начала цветения Ао начала созревания ягод у сорта Кёхо в экологических условиях 2018 года составица 50 Аней, что на 5 Аней короче, чем у контроцьного сорта и на 1 день короче, чем у столовых сортов на ампемоком екции. По продоцжительности периода от начама цветения Ао начама созревания ягод винограда Кёхо бциже всех бым к группе западно-европейских сортов и сортов бассейна Черного моря. Разница была в первом случае на Ава Аня больше, во втором - на Ава Аня меньше. Наибольшая разница быма с сортами восточной группы. У сорта Кёхо продолжительность периода от нача$\Lambda$ цветения до начама созревания ягод быма на 7 дней меньше, чем у сортов восточной группы [26]. Учитывая, что у изучаемого сорта Кохё продолжите ьность периода от начала цветения и до начама созревания ягод быма более короткой, то интенсивность роста ягод была бомее высокой по сравнению с контромем и группой столовых сортов в ампемокомлекции.

Полная физиологическая зрелость ягод у изучаемого сорта наступима 11 августа, практически одновременно с контролем - 12 августа и на 9 дней раньше, чем у столовых сортов в ампемокомлекции (табл.).

\section{Выводы}

Интродуцированный сорт Кёхо по показателям активного роста и прохождения фаз вегетации облаАает высоким адаптивным потенциалом в нестабимьных погодных условиях умеренно континентального кмимата юга России. В условиях острого Аефицита атмосферных осаАков и повышенной инсоляции ростовые и продукционные процессы у интродуцированного сорта Кёхо в 2018 году протекаци более интенсивно по сравнению с сортом местной селекции Бригантина. Продолжительность вегетации растений винограАа от распускания почек Ао полной физиологической зрелости ягод быма равна 119 Аней, на 5 Аней короче, чем у сорта Бригантина. Полная физиологическая зрелость ягод винограда Кёхо наступает 11 августа, одновременно с сортом Бригантина и на 9 Аней раньше, чем у большой группы столовых сортов разного эколого-географического происхожАения.

\section{Источники финансирования}

Не указан.

\section{Financing source}

Not specified.

\section{Конфликт интересов}

Авторы статьи подтверАими отсутствие конфмикта интересов, о котором необходимо сообщить. 


\section{Conflict of interest}

The authors confirmed the absence of conflict of interest, which must be reported.

\section{Список литературы/References}

1.Виноградарство: учебник / К.В. Смирнов, Л.М. Малтабар, А.М. Раджабов, Н.В. Матузок, Л.П. Трошин. М.: ФГБНУ «Росинформагротех», 2017. - 500 с.

[Smirnov K.V., Maltabar L.M., Radjabov A.M., Matuzok N.V., Troshin L.P. Vinogradarstvo: uchebnik [Viticulture: textbook]. Moskow, FGBNU Rosinformagroteh Publ., 2017. 500 p. (in Russian)]

2. Maghradze D., Rustioni L., Scienza A., Failla O. Phenological Diversity of Georgian grapevine Cultivars in Northern Itali. J. Am. Pomol. Soc. 2012, vol. 66, № 2, pp. $56-67$.

3. Фенология новых сортов винограда на юге Дагестана / А.Н. Алиева, Р.Ш. Джамалутдинова, А.Ш. Сулейманов, А.К. Курбанов // Виноделие и виноградарство. 2008. № 5. С. $38-39$.

[Aliyeva A.N., Jamalutdinova R.Sh., Suleymanov A.Sh., Kurbanov A.K. Phenology of new grape varieties in the south Dagestan. Vinogradarstvo i vinodelie [Winemaking and viticulture]. 2008, no. 5, pp. 38-39. (in Russian)].

4. Особенности прохождения фенофаз у новых сортов винограда в условиях предгорного Крыма (на примере белогородского района) / М.В. Мелконян, В.В. Лещенко, А.В. Суслов, В.А. Суслова, В.А. Волынкин // Магарач. Виноградарство и виноделие. 2001. № 4. С. 13 - 15.

[Melkonyan M.V., Leshchenko V.V., Suslov A.V., Suslova V.A., Volynkin V.A. Features of the passage of phenophases in new grape varieties in the conditions of foothill Crimea (on the example of the Belgorod region). Magarach. Vinogradarstvo i Vinodelie [Magarach. Viticulture and winemaking]. 2001, no. 4, pp. 13-15. (in Russian)]

5. Модонкаева А.Э., Полулях А.А. Основные фенологические фазы вегетационного периода ряда столовых сортов винограда // Виноделие и виноградарство. 2014. № 2. C. $40-43$.

[Modonkaeva A.E., Polulyakh A.A. The main phenological phases of the growing season of several table grape varieties. Vinogradarstvo i vinodelie [Winemaking and Viticulture], 2014, no. 2, pp. 40-43. Available at: http://www.foodprom. ru/archive/18-journals/vinodelie-i-vinogradarstvo/260vinodelie-i-vinogradarstvo-2-2014 (Accessed 15 April 2019). (in Russian)]

http://www.foodprom.ru/archive/18-journals/vinodelie-ivinogradarstvo/260-vinodelie-i-vinogradarstvo-2-2014

6.ФГБУ Госсорткомиссия РФ [Электронный ресурс] / https://reestr.gossort.com/ (дата обращения 16.04.19).

[FGBU Gossortcommissiya RF [State Cultivar Commission of the Russian Federation], Available at: https://reestr. gossort.com/ (accessed 16 April 2019).(in Russian) ]

7. Vondras A.M., Gouthu S., Schmidt J. A., Petersen A.-R. et al. The contribution of flowering time and seed content to uneven ripening initiation among fruits within Vitis vinifera L. cv. Pinot noir clusters. Planta, 2016, 243, no 5, pp. 1191-1202.

8.Макарова Г.А. Фенологическое развитие винограда в колочной степи Алтайского Приобья // Сибирский вестник сельскохозяйственной науки, 2007. № 9. С. 73 - 78.

[Makarova G.A. Phenological development of grapes in the steppe steppes of the Altai Ob region. Sibirskiy Vestnik sel'sko khozyastvennoy nauki [Siberian Bulletin of Agricultural Science], 2007. no. 9. pp. 73 - 78. (in
Russian).]

9. Dos Santos Cristiano Ezegueiel, Roberrto Sergio Ruffo, Jefferson Sato Alessandro, da Silva Jubileu Bruno. Caracterizacao da fenologiae da demanda termica das videiras "Cabernet Sauvignon" e "Tannat" para a regiao norte do Parana. Acta sci. Agron, 2007, 29, no. 3, pp. 361-366.

10. Burgos S., Almendros S., Fortier E. Facteurs environnementaux et phenologie de la vigne dans le canton de Geneve. Rev. Suisse Vitic. Arboric. Hortic, 2010, vol. 42, no 5, pp. 288- 295.

11. Caprio J.M. Quamme H.A. Weather conditions associated with grape production in the Okanagan Valley of British Columbia and potential impact of climate change. Canadian Journal of Plant Science, 2002, no. 82 (4), 2002. pp. 755-763.

12. Лазаревский М.А. Роль тепла в жизни европейской виноградной лозы. Изд-во Ростовского университета, ВНИИВиВ, 1961. 100 с.

[Lazarevsky M.A. The role of heat in the life of a European vine. Rostov-on-Don: Rostovskiy universitet, VNIINiV Publ., 1961, 100 p. (in Russian)]

13. Наумова Л.Г., Новикова Л.Ю. Тенденции продолжительности вегетации сортов винограда коллекции ВНИИВиВ им. Я.И. Потапенко // Виноделие и виноградарство. 2013. № 6. С. 48 - 53. http://www.foodprom. ru/archive/18-journals/vinodelie-i-vinogradarstvo/179vinodelie-i-vinogradarstvo-6-2013

[Naumova L.G., Novikova L.Yu. Trends in the duration of the growing season of varieties of grape collection VNIIViV nam. Ya.I. Potapenko. Vinogradarstvo i vinodelie [Winemaking and Viticulture], 2013, no. 6, pp. 48 - 53. Available at: http://www.foodprom.ru/archive/18journals/vinodelie-i-vinogradarstvo/179-vinodelie-ivinogradarstvo-6-2013 (accessed 16 April 2019). (in Russian)]

14. Spring J.-L., Viret O., Bloesch B. Phenologie de la vigne: 84 ans d'observation du chasselas dans le bissin lemanique. Rev. Suisse viticult., arboricult. et horticult, 2009, 41, no 3, pp. 151-155.

15. Петров В.С., Алейникова Г.Ю., Наумова Л.Г., Лукьянова А.А. Адаптивна реакция на лозови сортове в условия на климатични промени // Лозарство и винарство, 2018. № 6. C. 18 - 31.

[Petrov V.S., Aleinikova G.Yu., Naumova L.G., Lukyanova A.A. Adaptive response to grape's variety in conditions of climatic change. Lozarstvo i vinarstvo [Winemaking and Viticulture], 2018, no. 6, pp. 18 - 31. (in Bulgarian)].

16. Резултати од испитуваньето на степенот на оплодуванье кај сортите Мускат Хамбург и Афус али / Марковска-Кочовска Б., Илик-Попова С., Димовска В., Белески К. // Год. Зб. Земјод. Фак. Унив. «Кирил и Методиј». Скопје, 2001. Г. 46. С. 7 - 17.

[Markovska-Kochovska B., Ilik-Popova S., Dimovska V., Beleski K. Study findings on fertility of 'Muscat of Humburg' and 'Afus Ali' cultivars. Collection of works of the Faculty of Agriculture of the University of Cyril and Methodius. Skopje, 2001. G. 46, pp. 7-17. (in Macedonian)]

17. Jones G.V., Davis R.E. Climate Influences on Grapevine Phenology, Grape Composition, and Wine Production and Quality for Bordeaux, France. American Journal of Enology and Viticulture, 2000, no. 51(3), pp. 249-261.

18. Tomasi D., Jones G.V., Giust M., Lovat. L., Gaiotti F. Grapevine Phenology and Climate Change: Relationships and Trends in the Veneto Region of Italy for 1964-2009. 
Am J Enol Vitic, 2011, no. 62, p. 329-339.

19. Jones G.V., Duchene E., Tomasi E.D. et. al. Changes in European winegrape phenology and relationships with climate. Proceedings GESCO, 2005, Geisenheim, Germany.

20. Koufos G., Mavromatis T., Koundouras S., Fyllas N.M.Viticulture - Climate Relationships in Greece and Impacts of Recent Climate Trends: Sensitivity to "Effective" Growing Season Definitions. Advances in Meteorology, Climatology and Atmospheric Physics, Springer Atmospheric Sciences, 2012, pp. 555-561.

21. Pop N. Dinamics of the main phenophases in some table grape varieties under various ecopedological conditions. Bul. Univ. de stiinte agr. Si medicina, Cluj-Napoca. Ser. Horticultura, 2002, vol. 57, pp. 225-228.

22. Burgos S., Almendros S., Fortier E.. Facteurs environnementaux et phenologie de la vigne dans le canton de Geneve. Rev. Suisse viticult., arboricult. et horticult, 2010, 42, no 5, pp. 288-295.

23. Виноградарство столовых сортов. Монография / В.С. Петров, К.А. Серпуховитина, Т.А. Нудьга [и др.]; под общ. ред. Петрова В.С. Краснодар: ГНУ СКЗНИИСиВ, 2013. 304 c.

[Petrov V.S., Serpukhovitina K.A., Nud'ga T.A. et al. Vinogradarstvo stolovykh sortov. Monographya [Viticulture of table varieties. Monograph]. Krasnodar: GNU SKZNIISiV, 2013, 304 p. (in Russian)]

24. Современные методологические аспекты организации селекционного процесса в садоводстве и виноградарстве / под общ. ред. академика РАСХН Еремина Г.В. Краснодар: ГНУ СКЗНИИСиВ, 2012. 569 с.
[Sovremennye metodologicheskie aspekty organizatsii selektsionnogo protsessa $v$ sadovodstve $I$ vinogradarstve [Modern methodological aspects of the organization of the selection process in self-production and viticulture]. under total. ed. Academician of RAAS Eremin G.V. Krasnodar: GNU SKZNIISiV, 2012, 569 p. (in Russian)]

25. Лазаревский М.А. Изучение сортов винограда. Ростов н/Д: изд-во Ростов. ун-та, 1963. 150 с.

[Lazarevsky M.A. Izuchenie sortov vinograda [The study of grape varieties]. Rostov-on-Don: Rostovskiy universitet Publ., 1963, 150 p. (in Russian)]

26. Анапская ампелографическая коллекция (биологические растительные ресурсы): монография / Егоров Е.А., Ильина И.А., Петров В.С. и др. Краснодар: ФГБНУ Северо-Кавказский федеральный научный центр садоводства, виноградарства, виноделия, 2018. 194 с. https:// elibrary.ru/item.asp?id=36539666

[Egorov E.A, Ilyina I.A., Petrov V.S. [et al.] Anapskaya ampelograficheskaya kollektsyya (biologicheskie rastitel'nye resursy) monografiya [Anapa ampelographic collection (biological plant resources): monograph]. Krasnodar: FGBNU Severo-Kavkazskiy federal'nyy nauchnyy tsenter sadovodstva, vinogradarstva, vinodeliya, 2018, 194 p. (in Russian)]

ORCID ID:

Дергачев Д.В. https://orcid.org/0000-0001-5952-7593

Ларькина М.Д. https://orcid.org/0000-0002-6962-8256

Петров В.C. https://orcid.org/0000-0003-0856-7450

Панкин М.И. https://orcid.org/0000-0001-8807-8344 